\title{
A importância da noção de experiência no pensamento de D. W. Winnicott
}

\author{
The importance of the concept of experience \\ according to thought D.W. Winnicott's
}

Leopoldo FULGENCIO'

\begin{abstract}
Resumo
Com fundamento em pesquisas recentes sobre a relação entre a analítica existencial de Heidegger e a psicanálise de Winnicott, que destacam, por parte do psicanalista inglês em particular, a rejeição das especulações teóricas metapsicológicas, bem como sua busca pela experiência vivida e/ou a ser vivida, esta comunicação pretende explicitar a importância da noção winnicottiana de experiência, indicando algumas proximidades entre o modo como Winnicott pensa a psicanálise e o que seria esperado de uma psicologia científica construída com base na analítica existencial de Heidegger. Essa noção de experiência está presente em sua maneira de formular o que é o método de tratamento psicanalítico, que acrescenta à clássica concepção freudiana, resumida na fórmula "recordar, repetir, elaborar", outros sentidos e objetivos para o processo analítico, que ultrapassam a experiência relacionada à elaboração do inconsciente reprimido.
\end{abstract}

Unitermos: Elaboração do inconsistente. Experiência. Freud. Tratamento psicanalítico. Winnicott, Heidegger.

\begin{abstract}
Based on recentstudies on the relationship between Heidegger's existential analytic and Winnicott's psychoanalysis which put emphasis particularly on the rejection by the English psychoanalyst of the metapsychological theoretical speculations, as well as his search for the experience lived and/or to be lived, the purpose of this communication is to explain the importance of the concept of experience for Winnicott, by showing some connections between the way Winnicott sees psychoanalysis and what would be expected from a scientific psychology built from Heidegger's existential analytic. This concept of experience may be seen in the way he formulates the method of the psychoanalytical treatment, which adds to Freud's classical conception, summarized in the formula "remembering, repeating and working through", other meanings and objectives for the analytical process which go beyond the experience concerning the elaboration of the repressed unconscious.
\end{abstract}

Uniterms: Elaboration of inconscious. Experience. Freud. Psychoanalytical treatment. Winnicott, Heidegger.

Qual é ou como seria uma psicologia científica construída sob as bases da analítica existencial de Heidegger? É conhecido que Ludwig Binswanger e Medard Boss tentaram elaborá-la, mas até agora essa proposta não se mostrou adequada. Zeljko Loparic, por exemplo, apoiado nos próprios comentários de Heidegger sobre Binswanger e Boss, afirmou que essas duas propostas pecam pelos mesmos erros: elas filoso-

$\operatorname{cor}$

' Pontifícia Universidade Católica de Campinas, Centro de Ciências da Vida, Programa de Pós-Graduação em Psicologia. Av. Jonh Boyd Dunlop, s/n., Prédio Administrativo, Jd. Ipaussurama, 13090-950. Campinas, SP, Brasil. E-mail:<ful@that.com.br>. 
faram a ciência e cientificaram a filosofia, que se constituíram como pseudociência e pseudofilosofia. A esse respeito, diz Loparic:

A crítica de Heidegger [a Binswanger e a Boss] pode ser resumida na seguinte afirmação: a daseinanálise é uma construção que não pertence nem à ciência nem à filosofia; ela é pseudocientífica, por não ser capaz de definir cientificamente seus problemas factuais; e pseudofilosófica, por ser baseada em erros filosóficos categoriais graves. Os graves erros cometidos por Binswanger na sua leitura de Ser e tempo não foram, portanto, produtivos; pelo contrário, eles se revelaram desastrosos - essa é a avaliação de Heidegger - para o projeto da daseinanálise psiquiátrica como ciência ôntica dos distúrbios psíquicos (Loparic, 2002, p.402).

Todas as psicologias que se pretendem ciências naturais também ficam excluídas desse horizonte, uma vez que se colocam numa direção contrária à proposta de Heidegger. Permanece, então, a pergunta: haveria, no campo da psicologia científica, uma proposta psicoterápica que esteja construída de acordo com as exigências da não objetificação e do não determinismo naturalista para pensar e tratar o ser humano?²

Alguns estudos atuais apontam que a obra do psicanalista Donald Winnicott pode ser lida no contexto da analítica existencial heideggeriana (Dias, 2006; Loparic, 1988; 1999a; 1999b). Mas em que sentido isso poderia ser afirmado e mesmo verificado conceitualmente? Seguem-se alguns resultados de pesquisas que dão um início de resposta a essa questão. Por fim, pretendo mostrar que a noção de experiência segundo a teoria psicanalítica winnicottiana parece estar de acordo com a proposta de Heidegger.

Heidegger, nos Seminários de Zollikon, refere-se, dessta maneira, à teorização metapsicológica de Freud: "A metapsicologia de Freud é a transposição da filosofia neokantina [da natureza] ao ser humano. Por um lado, ele [Freud] usa as ciências naturais e, por outro, a teoria kantiana da objetividade" (Heidegger, 2001, p.222). Ao comentar a crítica de Heidegger a Freud, Loparic (1999b, p.112) afirma:
A crítica de Heidegger à teoria psicanalítica freudiana se dá em dois passos. A metapsicologia é inaceitável porque transfere ao estudo do homem, primeiro, a teoria kantiana da objetividade e, segundo, o paradigma das ciências da natureza (Heidegger, 1987, p. 260). Devido ao primeiro passo, Freud trabalha com uma inaceitável objetificação da historicidade do homem. Isto significa que ele vê o homem como algo meramente presente no mundo, ou seja, como apenas outro exemplo a mais de realidade efetiva. Em virtude do segundo passo, Freud naturaliza o homem como um processo causal. Tanto os fenômenos normais quanto os patológicos são vistos como resultados produzidos por impulsos e forças hipotéticas majoritariamente inconscientes. A 'história psicanalítica de uma vida humana', por exemplo, não é de modo algum uma história, mas uma 'cadeia causal natural, uma cadeia de causas e efeitos, e ainda por cima uma cadeia construída'.

Focado no estudo do modo como Freud teoriza, Fulgencio, em estudo anterior, mostrou o kantismo de Freud, caracterizando a natureza e a função da sua teorização metapsicológica, construída no quadro do programa transcendental kantiano para a pesquisa da natureza (Fulgencio, 2003; 2008b). Em um artigo de 2005 Fulgencio (2008a) conclui:

Em resumo, a metapsicologia não pode explicar os fenômenos clínicos nem constituir o sentido, ou parte do sentido, desses fenômenos, caso a palavra fenômeno seja tomada de acordo com o uso habitual, designando algo acessível à experiência clínica. A sua função é a de auxiliar a organização dos fatos, tornando possível estruturá-los e relacioná-los; ela é um constructo para conectar as descrições e uma orientação-guia para procurar (observar) novos dados. As especulações metapsicológicas não são nem fornecem explicações, mas estabelecem um quadro e uma direção para a busca de explicações factuais (empíricas) sobre os fenômenos psíquicos (Fulgencio, 2003, p.157).

Loparic, utilizando-se da noção de paradigma deThomaz Khun (Fulgencio, 2007; Loparic 2001b; 2006), colocou em evidência as diferenças entre os aspectos metafísicos da teoria psicanalítica freudiana e o modo

2 Pode-se encontrar na literatura secundária uma série de artigos que buscam analisar o que seria uma psicologia humanista de base fenomenológica, em consonância ou proximidade com a analítica existencial de Heidegger (Amattuzzi, 2009; Luczinski \& Ancona-Lopez, 2010). 
não metafísico como Winnicott concebe a teoria e a prática psicanalítica, explicitando diferenças entre os modelos ontológicos desses autores:

Começo pelo modelo ontológico do objeto de estudo da psicanálise. Enquanto a psicanálise tradicional estuda o psiquismo humano - concebido metapsicologicamente (especulativamente) como um aparelho movido a pulsões dirigidas para objetos (o papel central do relacionamento objetal sendo a satisfação) -, a winnicottiana jamais se distancia da "relação" factual indivíduo-ambiente, o indivíduo sendo caracterizado pela tendência para o amadurecimento e o ambiente, investido do papel de facilitador dessa tendência. De acordo com o preceito de manter abertas as pontes entre o paradigma antigo e o novo, Winnicott esforçar-se-á por preservar o que for possível da teoria antiga e, sobretudo, a eficácia clínica da psicanálise. Nesse espírito, os conceitos de pulsão, de "relação de objeto", de aparelho psíquico, de inconsciente etc. serão reinterpretados, isto é, transpostos para a linguagem experiencial do paradigma winnicottiano. Tal transposição não é uma simples tradução - visto que os conceitos metapsicológicos de Freud são, por definição, especulativos, isto é, não aplicáveis diretamente à experiência clínica -, mas algo semelhante a uma paráfrase para um campo semântico essencialmente diferente: o da linguagem que se quer essencialmente descritiva (Loparic, 2006, p.31).

No artigo"Winnicott e uma psicanálise sem metapsicologia", Fulgencio (2006) mostrou que Winnicott rejeitou os principais conceitos da metapsicologia freudiana, abandonando esse tipo de teorização:

Parece, pois, justificável conceitual e textualmente afirmar que Winnicott abandonou os conceitos de pulsão (Trieb), aparelho psíquico e libido, que estão respectivamente na base dos três pontos de vista que caracterizam a metapsicologia freudiana, propondo um tipo de teoria que tem uma ontologia e um conjunto de conceitos de natureza epistemológica diferentes daquela utilizada pela psicanálise freudiana ou tradicional. Não se trata, para Winnicott, de substituir a metapsicologia, a bruxa freudiana, por outra, mas de propor uma teoria psicanalítica sem esse tipo de especulação ou de feitiçaria (Fulgencio, 2006, p.417).

Trata-se de afirmar, em primeiro lugar, o que Winnicott não fez - não especulou com base em um modelo naturalista, caracterizando o homem como um aparelho movido por forças e energias -, para, então, procurar especificar mais claramente o que fez positivamente com suas propostas de desenvolvimento da teoria e da prática psicanalítica (por exemplo, Winnicott, 1965/1983, texto no qual explicita o que considera os objetivos do tratamento psicanalítico).

Como entender, no entanto, esse estudo na perspectiva traçada por Heidegger? Loparic especificou o ponto de vista filosófico em jogo, bem como as condições fundamentais para que uma ciência desse tipo pudesse ser elaborada:

Heidegger jamais apresentou qualquer proposta concreta a respeito das generalizações-guia quer da antropologia normal quer da patológica. Esta, aliás, é uma das razões que me levam a falar de um "projeto" de ciência do homem, e não de um "paradigma" heideggeriano para essa ciência. No entanto, ele especificou duas condições metodológicas e epistemológicas fundamentais negativas, que deveriam ser satisfeitas por qualquer generalização científica proposta para a ciência do homem: ela não deveria ser nem objetificante nem determinística (Loparic, 1999b, p.115)

Ao falar, por exemplo, dos valores que deveriam guiar uma perspectiva daseinsanalítica sobre o homem, Loparic comenta: "Os valores mais importantes que deveriam caracterizar a ciência daseinsanalítica do homem são eminentemente práticos e mesmo éticos: a saúde e a capacidade de alguém responsabilizar-se pelos seus próprios modos de ser" (Loparic, 1999b, p.117). Juntemos essa ideia à seguinte afirmação de Winnicott:

A vida de um indivíduo não se caracteriza mais por medos, sentimentos conflitantes, dúvidas, frustrações do que por seus aspectos positivos. O essencial é que o homem ou a mulher se sintam vivendo sua própria vida, responsabilizando-se por suas ações ou inações, sentindo-se capazes de atribuírem a si o mérito de um sucesso ou a responsabilidade de um fracasso. Pode-se dizer, em suma, que o indivíduo saiu da dependência para entrar na independência ou autonomia (Winnicott, 1971/1989a, p.30).

Se, numa aproximação rápida, lembramos como Winnicott entende a saúde, parece que estamos afirmando algo muito semelhante ao que diz Heidegger sobre o existir humano, sempre caracterizado como um existir-com. Ainda, nesse mesmo sentido, afirma Loparic, conectando Winnicott a Heidegger: 
Não há dúvida de que a saúde ou a doença dos bebês vistos por Winnicott não podem ser "produzidas" de modo algum, sendo sempre uma questão a ser decidida no decorrer das relações não-causais entre o bebê e seu ambiente humano. Mas isto não é tudo. Em sua essência, a psicopatologia winnicottiana nada tem a ver com o princípio da realidade, e tampouco com o princípio do prazer. A questão básica para os seres humanos é se vale ou não a pena viver a vida, independente do que isto possa custar, e não se ela se ajusta ao mundo externo ou se é agradável (Loparic, 1999b, p.127).

Tanto Loparic (2001 b; 2005; 2006; 2008) como Dias (2003; 2006) defendem que as mudanças propostas por Winnicott reformularam estruturalmente a psicanálise, dando a ela um lugar epistemológico diferente do dado por Freud. Retirando a psicanálise do seu quadro naturalista, Winnicott entende-a como uma ciência que não objetifica o homem nem o reduz a uma série de determinações causais (entre as representações que compõem o seu psiquismo), tais quais as da natureza em geral. Dias salienta: "A ideia que vem tomando corpo é que, com seu estudo da natureza humana, Winnicott teria dado início, sem saber e de forma ainda parcial, à ciência do homem que Heidegger vislumbrou ser possível, construída à luz da ontologia fundamental daseinsanalítica" (Dias, 2006, p.384).

Esse conjunto de referências parece, pois, corroborar a tese de que a analítica existencial de Heidegger é uma referência filosófica adequada ao tipo de ciência empírica proposta por Winnicott, que teria o objetivo de fazer um "estudo objetivo da natureza humana" (Winnicott, 1945/1997), sem, no entanto, objetificar o homem nem pensá-lo como determinado pelas mesmas leis causais que governam a natureza.

Nesse sentido, deve ser colocada em evidência a concepção de Winnicott a respeito da experiência como elemento necessário ao processo de cura, não só ao elaborar o passado recalcado e produzir ressignificação, mas levando em conta as novas experiências existenciais no curso do processo analítico. Sendo assim, a compreensão da noção de experiência em Winnicott pode contribuir para desenvolver e aprofundar o sentido da máxima clínica freudiana expressa no trinômio "recordar, repetir e elaborar".

Não se trata, nesta comunicação, de fazer uma análise crítica de todos os sentidos da noção de experiência no pensamento de Winnicott, seja analisando sua obra seja seus comentadores ${ }^{3}$ nem de apresentar criticamente as diferenças entre suas concepções e as de outros psicanalistas, mas sim de indicar a importância epistemológica dessa questão, da qual resultam mudanças tanto teóricas quanto práticas na compreensão do método de tratamento psicanalítico. Para isso, foram retomados alguns dos comentários de Winnicott, que afirmam ser a experiência (vivida no contexto de análise, mas não só nesse contexto) o fator preponderante para transformar os pacientes na direção da conquista da saúde.

Num texto em que analisa como surge o si-mesmo, relacionando-o com a atividade de ser no mundo por uma ação espontânea e criativa, Winnicott dirá que é justamente na experiência do brincar que se encontra a si mesmo: "É no brincar, e somente no brincar, que o indivíduo, criança ou adulto, pode ser criativo e utilizar sua personalidade integral: e é somente sendo criativo que o indivíduo descobre o eu (self)" (Winnicott, 1975a, p.80). O brincar é importante não só pelos conteúdos que expressa, mas em si mesmo (Winnicott, 1975b, p.61), como uma ação criativa do selfe um modo de ser no qual a ação criativa de brincar estabelece um modo de relação com o mundo criado e encontrado (fenômeno transicional) pelo self(Fulgencio, 2008a, uma análise do brincar winnicottiano como modelo do método de tratamento psicanalítico). Ao comentar aqueles que tiveram problemas nesse encontro de si mesmos e procuram ajuda, ele afirma, referindo-se a um dos sentidos da noção de experiência:

Aquele que procura nossa ajuda pode esperar sentir-se curado com nossas explicações. Poderia mesmo dizer: "Percebo o que quer dizer; eu sou eu mesmo

$\boldsymbol{\nabla \nabla \nabla v}$

3 Naffah Neto, por exemplo, faz uma análise do conceito de experiência em Winnicott, considerando "que toda experiência se produz no espaço potencial" (2007, p.231). Certamente, num artigo que visasse analisar e discutir em detalhes essa noção na obra de Winnicott, seria necessário explicitar a diferença entre a experiência de ser - como a primeira das experiências, como diz Winnicott (1994a, p.177), fundamento de toda experiência -, e sua diferença em relação à experiência cultural, que só pode ocorrer depois de um amadurecimento (integração) significativo da pessoa. Mas não é este o objetivo aqui proposto. 
quando me sinto criativo e quando executo um gesto criativo; a busca está terminada". Na prática, isso não acontece. Sabemos que, nesse tipo de trabalho, mesmo a explicação correta é ineficaz. A pessoa a quem estamos tentando ajudar necessita de uma nova experiência, num ambiente especializado. A experiência é a de um estado não-intencional, uma espécie de tiquetaquear, digamos assim, da personalidade não-integrada (Winnicott, 1975a, p.81).

Não se trata apenas (como pensava Freud) de fazer com que o paciente possa rememorar suas experiências passadas, completando as lacunas da sua memória (Freud, 1914), e dando outra significação àquilo que foi vivido. Para Winnicott, não é a compreensão verbal ou intelectual, mesmo que acompanhada de afeto, que possibilita ao paciente colocar-se a caminho de encontrar a si mesmo, mas tão-somente a realização de certas experiências no presente, sustentadas pelo setting analítico (ou seja, pela relação humana que a situação analítica pode proporcionar), que tornarão possível chegar, por si mesmo, ao encontro de si mesmo, nessa relação com o analista.

No brincar, descrito por Winnicott, temos tanto a base do si-mesmo como da vida grupal e cultural: "Para mim, o brincar conduz naturalmente à experiência cultural e, na verdade, constitui seu fundamento" (Winnicott, 1975c, p.147). Nessa mesma direção, cabe aqui lembrar o comentário de Phillips (1988), opondo a teoria da cultura de Freud à de Winnicott:

Enquanto Freud se preocupava com as enredadas possibilidades de satisfação pessoal de cada indivíduo, para Winnicott essa satisfação seria apenas parte do panorama mais amplo das possibilidades para autenticidade pessoal do indivíduo, o que ele chamará de "sentir-se real". Na escrita de Winnicott, a cultura pode facilitar o crescimento, assim como o pode a mãe; para Freud, o homem é dividido e compelido, pelas contradições de seu desejo, na direção de um envolvimento frustrante com os outros. Em Winncott, o homem só pode encontrar a si mesmo em sua relação com os outros, e na independência conseguida através do reconhecimento da dependência. Para Freud, em resumo, o homem era o animal ambivalente; para Winnicott, ele seria o animal dependente, para quem o desenvolvimento - a única "certeza" de sua existência - era a tentativa de se tornar "separado sem estar isolado". Anterior à sexualidade como o inaceitável, havia o desamparo.
A dependência era a primeira coisa, antes do bem e do mal (Phillips, 1988, p.29).

No seu artigo "Os objetivos do tratamento psicanalítico", de 1965, Winnicott defende o processo analítico como sendo, preponderantemente, um lugar para que determinadas experiências possam ser feitas. Para que essas experiências possam ocorrer, entretanto, um longo caminho de preparação das condições ambientais é necessário, em especial tudo aquilo que diz respeito à longa tarefa de constituição da confiabilidade ambiental e da possibilidade de depender desse ambiente (ou seja, do analista). Ele diz que, na fase inicial do tratamento, as interpretações (verbalizar a conscientização nascente em termos de transferência) são necessárias para criar as condições para que o paciente possa, então, fazer o fundamental, a saber (salienta ele referindo-se às outras duas fases do tratamento, seguintes a essa primeira):

Segue-se então uma longa fase [a segunda fase] em que a confiança do paciente no processo analítico acarreta todo tipo de experimentação, começando o paciente a ver como natural o sentimento de existir por si mesmo.

Na terceira fase o ego do paciente, agora independente, começa a se revelar e afirmar suas características individuais, começando o paciente a ver como natural o sentimento de existir por si mesmo (Winnicott, 1969/1987a, p.154)

Ele chega mesmo a lamentar, em 1969, dizendo que evitou muita mudança ao interpretar seus pacientes, adiantando-se a eles. Sobre isso, comenta Winnicott:

Só recentemente me tornei capaz de esperar; e esperar, ainda, pela evolução natural da transferência que surge da confiança crescente do paciente na técnica e no cenário psicanalítico, e evitar romper esse processo natural, pela produção de interpretações. Refiro-me à produção de interpretações e não às interpretações como tais. Estarrece-me pensar quanta mudança profunda impedi, ou retardei, em pacientes de certa categoria de classificação pela minha necessidade pessoal de interpretar. Se pudermos esperar, o paciente chegará à compreensão criativamente, e com imensa alegria [...] (Winnicott, 1969/1994b, p.121).

Winnicott percebeu, ao compreender que alguns pacientes precisam regredir a um estado de dependência, que a interpretação como desvelamento, feita 
pelo analista, era uma ação clínica que poderia ser inadequada. Referindo-se a um paciente que precisava regredir (à dependência) para que pudesse encontrar seu verdadeiro eu, Winnicott afirma:

A interpretação [ligando o sadismo oral e o erotismo com a transferência] era correta, mas chegou seis anos cedo demais, porque eu ainda não acreditava inteiramente na regressão. Para a minha própria segurança, eu precisava testar o efeito de pelo menos uma interpretação comum. Quando chegou o momento adequado para essa intervenção, ela não era mais necessária (Winnicott, 1955/1978, p.376).

Outra situação, relativa à ampliação da noção de experiência, precisa ainda ser comentada: a que ocorre a alguns pacientes, gravemente enfermos, que passaram por uma vivência para a qual não estavam ainda maduros, ou seja, eles viveram algo, entretanto, como ainda não estavam propriamente constituídos como uma identidade unitária, simplesmente não puderam experienciar o que viveram.

No seu artigo "Medo do colapso", de 1974, Winnicott afirma que alguns pacientes temem viver um tipo de loucura que na verdade já ocorreu, um colapso já vivido, mas que não pôde ser experimentado. Diz Winnicott:

Segundo minha experiência, existem momentos em que se precisa dizer a um paciente que o colapso, do qual o medo destrói-lhe a vida, já aconteceu. Trata-se de um fato que se carrega consigo, escondido no inconsciente. Este último aqui não é exatamente o inconsciente reprimido da psiconeurose, nem, tampouco, o inconsciente da formulação freudiana da parte da psique que se acha muito próxima do funcionamento neurofisiológico. Tampouco se trata do inconsciente de Jung, que eu diria ser todas aquelas coisas que se passam em cavernas subterrâneas, ou (em outras palavras) a mitologia do mundo, nas quais há um conluio entre o indivíduo e as realidades psíquicas internas maternas. Neste contexto especial, o inconsciente quer dizer que a integração do ego não é capaz de abranger algo. O ego é imaturo demais para reunir todos os fenômenos dentro da área da onipotência pessoal (Winnicott, 1974/1994c, p.73).

O que fica "guardado" não é nenhum conteúdo, mas algo que ainda não foi experienciado, algo que ficou, por assim dizer, congelado (cf., por exemplo, Winnicott, 62 1955/1978a, p.378) à espera de melhores condições ambientais e pessoais para ser, então, experienciado e integrado à personalidade total do paciente:"Em outras palavras, o paciente tem de continuar procurando o detalhe passado que ainda não foi experienciado, e esta busca assume a forma de uma procura deste detalhe no futuro" (Winnicott, 1974/1994c, p.73). Para fornecer um conteúdo mais intuitivo a tal fato, Winnicott o compara com o que ocorre com o bulbo e a flor à qual ele dará origem:

Tentando encontrar uma analogia, vi um bulbo de jacinto a ser plantado em uma tigela. Pensei: há um odor maravilhoso trancado naquele bulbo, embora soubesse, naturalmente, não existir um lugar no bulbo em que o odor se ache trancado. A dissecação do bulbo não proporcionaria a quem a fizesse a experiência de uma fragrância de jacinto, se o lugar apropriado estivesse por ser alcançado. Apesar disso, existe no bulbo um potencial que acabará se tornando um perfume característico, quando a flor se abrir. Isto não passa de uma analogia, mas poderia transmitir um retrato do que estou tentando enunciar. Faz parte importante de minha tese que a loucura ou o colapso de defesas originais, se viesse a ser experienciado, seria indescritivelmente doloroso (Winnicott, 1994d, p.99).

Ao caracterizar, de uma maneira que ele diz simplificada, mas que coloca a experiência no centro do seu método de tratamento, Winnicott comenta:

No exemplo mais simples possível, uma pessoa que
está sendo analisada consegue corrigir uma expe-
riência passada, ou uma experiência imaginária, ao
revivê-la em condições simplificadas nas quais a dor
pode ser tolerada porque está sendo distribuída ao
longo do período de tempo; tomada, por assim dizer,
em pequenas doses, num meio ambiente emocional
controlado. Como vocês bem podem imaginar, na
prática concreta raramente existe algo tão descom-
plicado como isso, mas o contexto principal pode
legitimamente ser descrito desta maneira (Winnicott,
1945/1997, p.36).

A maneira como Winnicott concebe os objetivos do tratamento psicanalítico - segundo sua noção de saúde, que considera a doença sinônimo de imaturidade (Winnicott, 1987b, p.265) - leva-o a ponderar que o paciente não precisa apenas rememorar e ressignificar seu inconsciente recalcado (Winnicott, 1989b, p.108), mas deve ter novas experiências inter-humanas (em especial 
as que poderá ter com seu analista) que permitam a ele integra-se num si mesmo como uma pessoa inteira.

Num sentido complementar a esse, a experiência do brincar, em si mesma, e a possibilidade de integração de um passado que não foi possível de ser experienciado são novas modalidades da experiência que não são redutíveis ao trabalho de elaboração relativa ao inconsciente recalcado. Com essa compreensão da noção de experiência, pode-se considerar que Winnicott contribuiu para um desenvolvimento do que significa"recordar, repetir e elaborar" como direção do processo analítico.

Para finalizar, fazendo não propriamente uma conclusão, mas apenas indicando mais um aspecto da noção de experiência em Winnicott, que não tem a ver com o inconsciente recalcado, Fulgencio aponta para a maneira pela qual Winnicott caracteriza a morte como sendo a última das experiências do estar vivo (Winnicott, 1988, p.30), ou seja, como a última experiência integrativa do processo de amadurecimento: "a possibilidade e realmente a certeza da morte; e, com a aceitação da morte advém um grande alívio, alívio do medo das alternativas, tais como a desintegração ou os fantasmas - ou seja, a sobrevivência de fenômenos espíritas, para depois da morte da parceria psicossomática" (Winnicott, 1989c, p.48). É justamente por isso que Winnicott tem a expectativa, expressa na sua autobiografia inacabada, de poder estar vivo para poder selar a existência com essa experiência (C. Winnicott, 1989, p.3): "Oh, Deus! Possa eu estar vivo quando morrer".

\section{Referências}

Amatuzzi, M. M. (2009). Psicologia fenomenológica: uma aproximação teórica humanista. Estudos de Psicologia (Campinas), 26 (1), 93-100. doi: 10.1590/S0103-166X20 09000100010.

Dias, E. O. (2003). A teoria do amadurecimento de D. W. Winnicott. Rio de Janeiro: Imago Editora.

Dias, E. O. (2006). Winnicott e Heidegger: temporalidade e esquizofrenia. Revista de Filosofia e Psicanálise Natureza Humana, 8 (Especial 1), 383-400.

Freud, S. (1914). Remémoration, répétition et perlaboration. In Oeuvres complètes. Psychanalyse (Vol. 12, pp.187-196). Paris: PUF.

Fulgencio, L. (2003). As especulações metapsicológicas de Freud. Revista de Filosofia e Psicanálise Natureza Humana, $5(1), 127-164$.
Fulgencio, L. (2006). Winnicott e uma psicanálise sem metapsicologia. Revista de Filosofia e Psicanálise Natureza Humana, 8 (Especial 1), 401-420.

Fulgencio, L. (2007). Paradigmas na história da psicanálise. Revista de Filosofia e Psicanálise Natureza Humana, 9 (1), 97-128.

Fulgencio, L. (2008a). O brincar como modelo do método de tratamento psicanalítico. Revista Brasileira de Psicanálise, 42 (1), 124-136.

Fulgencio, L. (2008b). O método especulativo em Freud. São Paulo: EDUC.

Heidegger, M. (1927). Sein und Zeit. Tübingen: Niemeyer.

Heidegger, M. (1987). Zollikoner Seminare. Frankfurt Klostermann.

Heidegger, M. (2001). Seminários de Zollikon. Petrópolis: Vozes.

Loparic, Z. (1998). Psicanálise: uma leitura heideggeriana. Veritas, 43 (1), 25-41.

Loparic, Z. (1999a). É dizível o inconsciente? Revista de Filosofia e Psicanálise Natureza Humana, 1 (2), 323-385.

Loparic, Z. (1999b). Heidegger and Winnicott. Revista de Filosofia e Psicanálise Natureza Humana, 1 (1), 104-135.

Loparic, Z. (2001a). Além do inconsciente: sobre a desconstrução heideggeriana da psicanálise. Revista de Filosofia e Psicanálise Natureza Humana, 3 (1), 91-140.

Loparic, Z. (2001b). Esboço do paradigma winnicottiano. Cadernos de História e Filosofia da Ciência, 11 (2), 7-58.

Loparic, Z. (2002). Binswanger, leitor de Heidegger: um equívoco produtivo? Revista de Filosofia e Psicanálise Natureza Humana, 4 (2), 383-413.

Loparic, Z. (2005). Elementos da teoria winnicottiana da sexualidade. Revista de Filosofia e Psicanálise Natureza Humana, 7 (2), 311-358.

Loparic, Z. (2006). De Freud a Winnicott: aspectos de uma mudança paradigmática. Revista de Filosofia e Psicanálise Natureza Humana, 8 (Especial 1), 21-47.

Loparic, Z. (2008). O paradigma winnicottiano e o futuro da psicanálise. Revista Brasileira de Psicanálise, 42 (1), 137-150.

Luczinski, G. F., \& Ancona-Lopez, M. (2010). A psicologia fenomenológica e a filosofia de Buber: o encontro na clínica. Estudos de Psicologia (Campinas), 27 (1), 73-82. doi: 10.1590/S0103-166X2010000100009.

Naffah Neto, A. (2007). A noção de experiência no pensamento de Winnicott como conceito diferencial na história da psicanálise. Revista de Filosofia e Psicanálise Natureza Humana, 9 (2), 221-242.

Phillips, A. (1988). Winnicott. São Paulo: Ideias \& Letras, 2007

Winnicott, C. (1989). D.W.W.: uma reflexão. In Explorações psicanalíticas. Porto Alegre: Artes Médicas.

Winnicott, D. W. (1975a). O brincar: a atividade criativa e a busca do eu (self). In O Brincare a realidade. Rio de Janeiro: Imago.

Winnicott, D. W. (1975b). O brincar: uma exposição teórica. In O Brincar e a realidade. Rio de Janeiro: Imago. 
Winnicott, D. W. (1975c). A criatividade e suas origens. In 0 Brincar e a realidade. Rio de Janeiro: Imago.

Winnicott, D.W. (1978). Aspectos clínicos e metapsicológicos da regressão no contexto psicanalítico. In Da Pediatria à psicanálise. Rio de Janeiro: Francisco Alves. (Originalmente publicado em 1955).

Winnicott, D. W. (1983). Os objetivos do tratamento psicanalítico. In O Ambiente e os processos de maturação. Porto Alegre: Artes Médicas. (Originalmente publicado em 1965).

Winnicott, D. W. (1987a). Darão as escolas progressistas excesso de liberdade à criança? In Privação e delinqüência. São Paulo: Martins Fontes. (Originalmente publicado em 1969).

Winnicott, D. W. (1987b). Variedades de psicoterapia. In Privação e delinqüência. São Paulo: Martins Fontes.

Winnicott, D. W. (1988). Natureza humana. Rio de Janeiro: Imago.

Winnicott, D. W. (1989a). O conceito de indivíduo saudável. In Tudo começa em casa. São Paulo: Martins Fontes. (Originalmente publicado em 1971).
Winnicott, D. W. (1989b). A cura. In Tudo começa em casa. São Paulo: Martins Fontes.

Winnicott, D. W. (1989c). Sum: eu sou. In Tudo começa em casa. São Paulo: Martins Fontes, 1989.

Winnicott, D. W. (1994a). Material clínico. In Explorações psicanalíticas. Porto Alegre: Artes Médicas.

Winnicott, D. W. (1994b). O uso de um objeto e o relacionamento através de identificações. In Explorações psicanalíticas. Porto Alegre: Artes Médicas. (Originalmente publicado em 1969).

Winnicott, D. W. (1994C). O medo do colapso. In Explorações psicanalíticas. Porto Alegre: Artes Médicas.

Winnicott, D. W. (1994d). Psiconeurose na infância. In Explorações psicanalíticas. Porto Alegre: Artes Médicas.

Winnicott, D. W. (1997). Para um estudo objetivo da natureza humana. In Pensando sobre crianças. Porto Alegre: Artes Médicas. (Originalmente publicado em 1945).

Recebido em: 21/8/2008

Versão final reapresentada em: 21/7/2010

Aprovado em: 29/10/2010 